Article

\title{
Dynamic 3D Simulation of Flood Risk Based on the Integration of Spatio-Temporal GIS and Hydrodynamic Models
}

\author{
Yongxing $W_{u}{ }^{1,+}+\mathbb{C}$, Fei Peng ${ }^{1,+}+\mathbb{D}$, Yang Peng ${ }^{2}$, Xiaoyang Kong ${ }^{1}$, Heming Liang ${ }^{1}$ and Qi Li ${ }^{1, *}$ \\ 1 Institute of Remote Sensing and GIS, Peking University, Beijing 100871, China; yongxing@pku.edu.cn (Y.W.); \\ rsfeipeng@gmail.com (F.P.); 1701110577@pku.edu.cn (X.K.); liangheming@pku.edu.cn (H.L.) \\ 2 School of Renewable Energy, North China Electric Power University, Beijing 102206, China; \\ pengyang@ncepu.edu.cn \\ * Correspondence: liqi@pku.edu.cn; Tel.: +86-10-6275-5022 \\ + These authors contributed equally to this work.
}

Received: 26 September 2019; Accepted: 13 November 2019; Published: 18 November 2019

\begin{abstract}
Dynamic visual simulation of flood risk is crucial for scientific and intelligent emergency management of flood disasters, in which data quality, availability, visualization, and interoperability are important. Here, a seamless integration of a spatio-temporal Geographic Information System (GIS) with one-dimensional (1D) and two-dimensional (2D) hydrodynamic models is achieved for data flow, calculation processes, operation flow, and system functions. Oblique photography-based three-dimensional (3D) modeling technology is used to quickly build a 3D model of the study area (including the hydraulic engineering facilities). A multisource spatio-temporal data platform for dynamically simulating flood risk was built based on the digital earth platform. Using the spatio-temporal computation framework, a dynamic visual simulation and decision support system for flood risk management was developed for the Xiashan Reservoir. The integration method proposed here was verified using flood simulation calculations, dynamic visual simulations, and downstream river channel and dam-break flood simulations. The results show that the proposed methods greatly improve the efficiency of flood risk simulation and decision support. The methods and system put forward in this study can be applied to flood risk simulations and practical management.
\end{abstract}

Keywords: spatio-temporal GIS; hydrodynamic model; spatio-temporal computation framework; flood risk; 3D simulation

\section{Introduction}

Water is important for human survival, but it is also the source of many disasters. According to the 2018 disaster report for China, flood disasters are one of the main natural disasters for the country [1]. It is crucial for ecologically-based development to understand how to scientifically prevent flood disasters and protect and properly use water resources. Hydrodynamic models are core quantitative calculations in emergency flood disaster management [2-4] and can accurately simulate the instantaneous dynamic evolution and medium- to long-term development of a flood [5]. Since hydrodynamic models are very complicated, usually only domain experts can understand the models. Therefore, three-dimensional (3D) visualization of the computation results is important in practice. In recent years, texture mapping technology, animation technology, and simulation technology have been used to build 3D virtual environments based on data such as LiDAR point clouds, satellite images, contour lines, and topographic maps. By using digital hydrodynamic models to calculate the water depth and flow velocity, flood evolution and inundated areas could be simulated and displayed in a 3D virtual environment, thus enhancing decision-makers', the public's, and other stakeholders' 
awareness of floods. It will also promote scientific management of flood disasters [6-9]. Although the effect of visualization (such as rainfall and rollback waves) in these studies is reasonably well presented [8], most of them use simulation software or animation technology to show the effects of floods and inundated areas at different times [9]. The flexibility of 3D presentations and spatial analysis functions should be strengthened. For example, queries of water depth at an arbitrary point and displays of flowrate and direction are not supported in a 3D virtual environment. On the one hand, 3D virtual environments have not been seamlessly integrated with hydrodynamic models, which read the computation results of hydrodynamic models (such as text files). On the other hand, terrain topology is established by using contours of topographic maps. This method takes longer to process, and its precision depends on the scale and production time of the map $[7,8]$. Along with oblique photogrammetry, the seamless integration of spatio-temporal GIS and hydrodynamic models provide a way to solve the problem.

Based on a unified spatio-temporal reference, spatio-temporal datasets comprise geographic elements or phenomena related to a location [10]. Spatio-temporal data have a spatial dimension (S), an attribute dimension (D), and a time dimension (T) [11]. Space-time data reflect quantitative and qualitative characteristics, the spatial structure and the spatial relationships among the geographical elements or phenomena, and their changes through time [12,13]. Spatio-temporal data are the basis for how humans understand the geographical world. A spatio-temporal Geographic Information System (GIS) is able to acquire, store, analyze, and visualize spatio-temporal data. It represents the position and spatial form of geographic objects or phenomena, and their changes over time. Compared with two-dimensional (2D) GIS and three-dimensional (3D) GIS, spatio-temporal GIS is more powerful for visualization and spatial analysis and can more accurately reflect how objects change [14-16]. Over time, an increasing amount of meteorological data have become available. The costs of high-resolution satellite images and oblique photogrammetric surveys have been reduced, and their reliability has improved. The new generation of information technologies (such as the Internet of Things (IoT), big data, and cloud computing) have rapidly developed and are increasingly applied in the water industry [17]. As a result, the number of data types has increased, and the volume of data has grown rapidly. These developments have enabled real-time simulations of flood risk and intelligent emergency management. In addition, there is an increased demand for data management, visualization, spatial analysis, and business integration. These developments have also led to changes from static 3D data to dynamic 3D data and time series data, from static to dynamic and continuous visualizations, from spatial analysis to real-time spatio-temporal simulations, and from decision support aids to operational running. Spatio-temporal GIS can better satisfy these changes, can better manage spatio-temporal data from flood disasters, and can be used to reveal patterns of spatio-temporal changes in incidents (i.e., floods) [18-21].

Hydrodynamic models are very complicated and involve large amounts of data [6-9]. The application value of a hydrodynamic model is affected by the following factors: (a) The availability, timeliness, and resolution of basic data pertaining to the river channel and its surroundings; (b) the effect of the visualization of the computation results; and (c) the extent to which the hydrodynamic models and the business system are integrated. The disaster-inducing factors of flood risk include the flood volume, the inundated area, the inundated depth, the inundation duration, the flood flow velocity, and the flow direction. Changes in the flood flow velocity, the flow, and the water level through time are important for decision making in flood disaster emergency management [22]. Spatio-temporal GIS methods allow three-dimensional visualizations of the locations and conditions of hydraulic engineering facilities, hydrological information, meteorological data, flood factors, and the results of model computations. This type of GIS can visually and dynamically show spatio-temporal changes in floods and the spatial distribution of affected persons, facilities, and ecological environments [23,24]. It provides dynamic, quantitative, refined, and real-time information for decision making by flood evolution simulations, condition evaluation of hydraulic engineering facilities, disaster evaluation, and emergency management. Additionally, it can provide powerful data and platform support for early disaster warning systems and monitoring and evaluation 
of flood disasters [25-27]. Spatio-temporal GIS uses high-precision and high-resolution spatio-temporal data and dynamic visualization effects. It has greatly enhanced flood simulations, flood disaster forecasts, and early warning and emergency management of flood disasters. It provides a valid solution to data quality and visualization problems in hydrodynamic model computations [24]. The seamless integration of spatio-temporal GIS and hydrodynamic models will considerably solve the three problems that affect the application value of hydrodynamic models.

This study presents a technical method for quickly establishing a spatio-temporal GIS framework for a reservoir, river, and the surrounding areas using an oblique photogrammetric survey and the digital earth platform. This method allows the seamless integration of the spatio-temporal GIS framework with the hydrodynamic models. A platform for the dynamic simulation of flood risk was established; this platform can integrate data flow, business flow, computation resources, and visual decision making. The platform provides basic data, such as riverbed section locations and a regional digital elevation model (DEM), which are required for the hydrodynamic model computations. The resulting values, including the flow velocity, flow direction, water depth, and inundated range, are displayed in an integrated, dynamic, and three-dimensional way. The platform can also show the variations in the flood factors in three dimensions, relative to changes in the input parameters such as the rainfall and reservoir flood discharge. This platform provides quantitative, scientific, efficient, and visual decision support information for flood simulations, early flood disaster warning systems, and water resources management. A flood-dispatching dynamic and visual simulation platform for the Xiashan Reservoir and the Weihe River was established. The platform provides web-end functions, including data management, data query, model computation, flood simulation, and visual decision making. The methods described here are of great significance for the emergency management of flood disasters and for the intelligent dispatching of water resources in the era of IoT, big data, and cloud computing [17].

\section{Materials and Methods}

\subsection{Method for Rapidly Building a Spatio-temporal GIS Platform for Flood Risk Simulation}

\subsubsection{Data Acquisition Through Oblique Photography}

A multi-lens oblique photography system was used to photograph the ground, based on the position of exposure points, to obtain multi-angle ground images with multiple degrees of overlap. With its enhanced performance and more convenient operations of graphics processing units (GPU), cloud computing, unmanned aerial vehicles, and digital cameras, oblique photography can rapidly generate a high-precision and high-resolution three-dimensional model of the physical world. This three-dimensional model can be resolved at the centimeter scale, which can truly and objectively represent the land surface configuration $[28,29]$ (Table 1 ).

Table 1. Key quality requirements for high-definition image data and landform data.

\begin{tabular}{cc}
\hline Parameter & Quality Requirements \\
\hline Coordinate & $\begin{array}{c}\text { WGS-84 longitudinal and latitudinal } \\
\text { coordinates, Gaussian projection }\end{array}$ \\
\hline Elevation & 1985 National Elevation Reference \\
\hline DOM Resolution & No less than $0.2 \mathrm{~m}$ \\
\hline DEM & Scale greater than 1:2000 \\
\hline
\end{tabular}

Abbreviations: DOM, digital orthophoto map; DEM, digital elevation model.

The data from oblique photography were processed using smart3D. Photos captured from different angles were used as data sources for smart3D to read the information, such as photo locations and control points. Smart3d output 3D models of terrain and buildings with real textures without manual 
intervention, which could accurately show the geometrical morphology and detailed composition of ground objects. The processing flow is shown in Figure 1. A triangulation network (TIN) was established using a dense point cloud generated by aerial triangulation and the dense matching of images [30]. The TIN forms an untextured model that can reflect the 3D spatial form of objects. Calculating the corresponding texture from the images using the software and mapping the texture on the corresponding untextured model can form a real 3D scene that reflects the spatial relationships and surface features of objects. Then, data, such as digital orthophoto maps (DOMs), digital elevation models (DEMs), DSMs, 3D models (3DMs), DLG (Digital Line Graphic) and digital object models (DOBs), can be generated as needed.

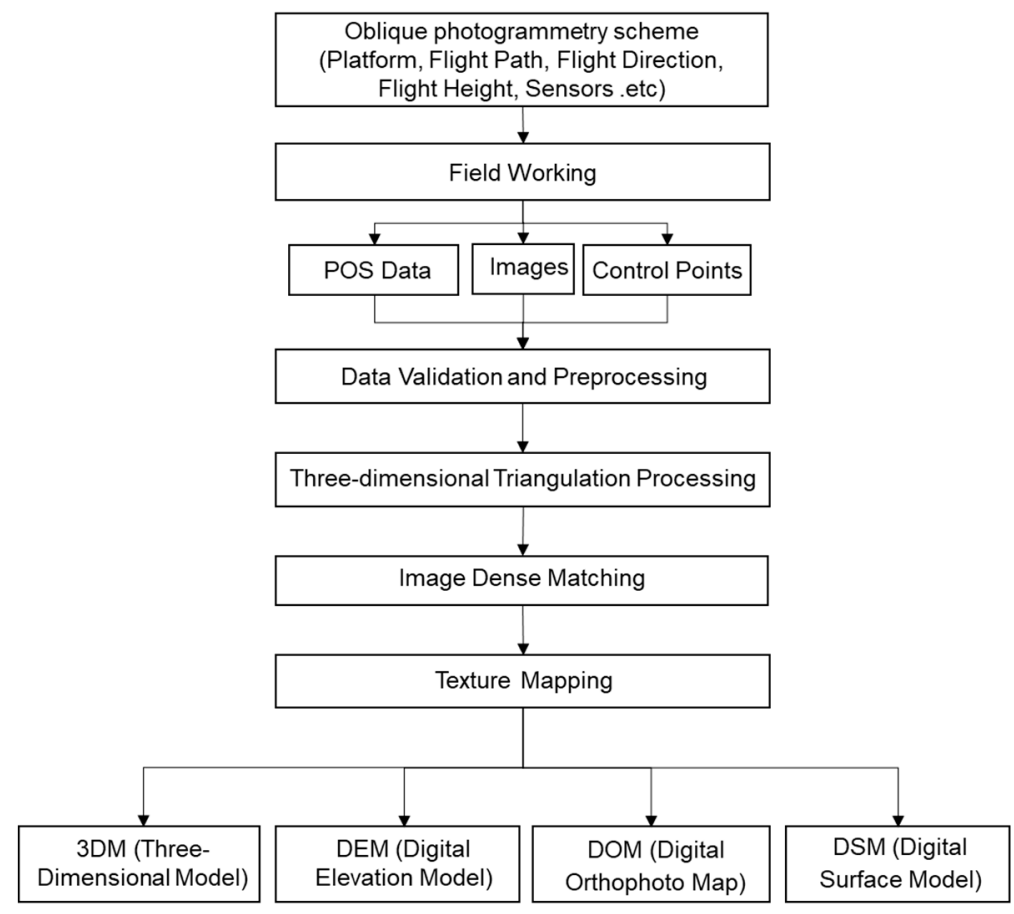

Figure 1. Schematic diagram of the complete data processing flow for oblique photography-based three-dimensional (3D) modeling.

\subsubsection{Construction of 3D Models for Hydraulic Facilities}

In this study, three-dimensional models of hydraulic facilities were constructed for separate queries, spatial analyses, connecting time series data of sensors, and so on. The model precision standards refer to those listed in Table 2.

Table 2. Unified accuracy reference for features of a 3D model.

\begin{tabular}{|c|c|c|c|c|c|}
\hline $\begin{array}{l}\text { Precision } \\
\text { Index }\end{array}$ & $\begin{array}{c}\text { Plane } \\
\text { Precision }\end{array}$ & $\begin{array}{l}\text { Height } \\
\text { Difference } \\
\text { Precision }\end{array}$ & $\begin{array}{c}\text { Plane } \\
\text { Precision of } \\
\text { Other Features }\end{array}$ & $\begin{array}{l}\text { Intrinsic } \\
\text { Precision } \\
\text { of Features }\end{array}$ & $\begin{array}{l}\text { Precision of the Measured } \\
\text { Spacing between Points, Lines, } \\
\text { and Planes of any Feature }\end{array}$ \\
\hline $\begin{array}{l}\text { Precision } \\
\text { requirement }\end{array}$ & $\leq 30 \mathrm{~cm}$ & $\leq 30 \mathrm{~cm}$ & $\begin{array}{l}\leq 50 \mathrm{~cm} \text { and less } \\
\text { than } 10 \% \text { of the } \\
\text { spacing between } \\
\text { measured objects }\end{array}$ & $\begin{array}{l}\leq 30 \mathrm{~cm} \text { and less } \\
\text { than } 10 \% \text { of the } \\
\text { spacing between } \\
\text { measured objects }\end{array}$ & $\begin{array}{l}\leq 50 \mathrm{~cm} \text { and less than } 10 \% \text { of the } \\
\text { spacing between } \\
\text { measured objects }\end{array}$ \\
\hline
\end{tabular}

To create the three-dimensional models, the contour lines of the hydraulic engineering facilities were imported into the modeling software. The outline structures of the reservoir dam and its appurtenance were obtained through a general survey. Editing of all models was completed in 3ds Max. 


\subsubsection{Building of a 3D Scene for Flood Risk Simulation}

Using LOD (level of detail) technology and by integrating spatial data at different scales, the real 3D scene was built to provide data, a computing platform, and visualization support for the dynamic simulation of flood risk in the spatio-temporal GIS framework [26,27] (the building process is shown in Figure 2). The large-scale data include a 1:10,000 topographic map and a 2.5-m resolution image of the study area and the surrounding areas within a certain range. The medium-scale data are the oblique photography-based 3D modeling data within the study area, including the DEM, DOM, and 3DM. The small-scale data include the 3D single-body models of the hydraulic engineering facilities and the 3D models of the equipment and facilities in buildings, such as the pump stations. The 3D scene generated from oblique photography (osgb format) was directly used in the 3D models of key areas. The textured 3D terrains were generated by superimposing the satellite image on DEM, which were used as the 3D models of the rest areas. These two 3D scenes and single 3D models of water conservancy facilities were imported into spatio-temporal GIS. The whole study area could then be displayed in a three-dimensional way through the spatio-temporal GIS.

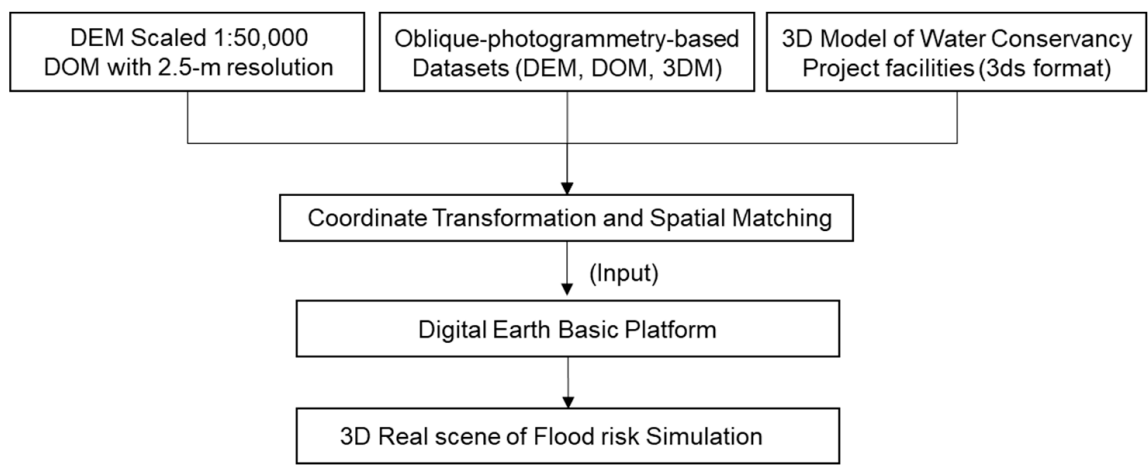

Figure 2. Process of 3D scene construction for flood risk simulation.

\subsection{Hydrodynamic Models}

For simulating spatio-temporal variations in the river channel flow upstream and downstream of the reservoir and early warnings of flooding in the watershed, we selected the 1D and 2D hydrodynamic models to perform quantitative simulations of the flooding process in the downstream river channel, based on current and historical measured hydrological variables (including rainfall, discharge, and water level) [31,32]. The data required by the model and the output results are provided in Table 3.

Table 3. Relevant parameters for the hydrodynamic model system.

\begin{tabular}{cc}
\hline Input Parameters & Output Parameters \\
\hline Topographic data of the river channel & $\begin{array}{c}\text { Water level, flow process } \\
\text { Upstream and downstream discharge and water level } \\
\text { Measurement data of the flood detention area }\end{array}$ \\
$\begin{array}{c}\text { Name, width, and sill elevation of the flood diversion gate } \\
\text { Measured water level and discharge of the water channel }\end{array}$ & $\begin{array}{c}\text { Flood routing process in the flood detention area } \\
\text { Inundated processes of the flood detention area } \\
\text { Storage process of the flood detention area }\end{array}$ \\
\hline
\end{tabular}

\subsubsection{One Dimensional (1D) Unsteady Flow Model of the River Network}

One-dimensional unsteady flow movement in a single river channel is often described using the Saint-Venant equations [31,33] — namely, the continuity equation of flow (Equation (1)) and the dynamic equation of flow (Equation (2)) —as follows:

$$
\frac{\partial Q}{\partial x}+B \frac{\partial Z}{\partial t}=q_{1}
$$




$$
\frac{\partial Q}{\partial t}+\frac{\partial}{\partial x}\left(\alpha_{1} \frac{Q^{2}}{A}\right)+g A \frac{\partial Z}{\partial x}+g \frac{n^{2} Q|Q|}{A R^{4 / 3}}=q_{1}\left(u_{1}-V\right)
$$

where $t$ is time (s); $x$ is the flow path (m); $Q$ is the discharge; $A$ is the cross-sectional area of flow; $B$ is river width; $Z$ is the water level; $R$ is the hydraulic radius; $n$ is the Manning roughness coefficients; $V$ is the average flow velocity of the section; $q_{l}$ and $u_{l}$ are the lateral inflow per unit length of the river reach and the component of the lateral inflow in the $\mathrm{x}$ direction; $\alpha_{1}$ is the momentum correction factor, where $\alpha_{1}=\left(\int_{A} u^{2} d A\right) /\left(Q^{2} / A\right)$, and $g$ is the gravitational acceleration.

Flow and energy in single river reaches are exchanged at the bifurcation point. Therefore, movement of flow at the bifurcation point must conserve mass and energy. In other words, a balance between the net flux at the bifurcation point and the net change of the actual water volume at the bifurcation point (Equation (3)) must be maintained, as described in the equation as follows:

$$
\sum Q_{i}=\frac{\partial \Omega}{\partial t}
$$

where $Q_{i}$ is the influx at the bifurcation point after passing through cross-section $I$ and the influx at the bifurcation point (node) is positive, while the outflux at the bifurcation point (node) is negative. $\Omega$ is the water storage capacity of the bifurcation point. Considering the velocity head, resistance loss, and other factors at the end point of river reaches at the bifurcation point, the water levels at the end points of all river reaches at the bifurcation point shall meet the following requirements (Equation (4)):

$$
\begin{gathered}
Z_{i}=Z_{j}=\ldots \ldots=\bar{Z} \\
\Delta Z_{i}=\Delta Z_{j}=\ldots \ldots=\Delta \bar{Z}
\end{gathered}
$$

If the section of the river reaches connected by the bifurcation point is very close to the bifurcation point, resistance loss at the bifurcation point will be negligible. Therefore, it can be assumed that the water level at the end points of all river reaches at the bifurcation point is the same.

Equations (1) and (2) can be solved using numerical techniques [34]. The solution to these equations comprises estimates of $Q$ and $Z$ for every cross-section at each time step.

\subsubsection{Two-Dimensional (2D) Flow Routing Model of the Downstream River Channel}

Generally, the 2D flow equation for the plane flood routing in the flood detention area can be described using the shallow water equation $[35,36]$. The continuity equation of flow (Equation (5)) is as follows:

$$
\frac{\partial Z}{\partial t}+\frac{1}{C_{\xi} C_{\eta}} \frac{\partial}{\partial \xi}\left(h u C_{\eta}\right)+\frac{1}{C_{\xi} C_{\eta}} \frac{\partial}{\partial \eta}\left(h v C_{\xi}\right)=0
$$

The dynamic equations of flow (Equations (6) and (7)) are as follows:

$$
\begin{gathered}
\frac{\partial u}{\partial t}+\frac{1}{C_{\xi} C_{\eta}}\left[\frac{\partial}{\partial \xi}\left(C_{\eta} u^{2}\right)+\frac{\partial}{\partial \eta}\left(C_{\xi} v u\right)+v u \frac{\partial C_{\xi}}{\partial \eta}-v^{2} \frac{\partial C_{\eta}}{\partial \xi}\right]=-g \frac{1}{C_{\xi}} \frac{\partial Z}{\partial \xi}+f v \\
-\frac{u \sqrt{u^{2}+v^{2} n^{2}}}{h^{4 / 3}} g+\frac{1}{C_{\xi} C_{\eta}}\left[\frac{\partial}{\partial \xi}\left(C_{\eta} \sigma_{\xi \xi}\right)+\frac{\partial}{\partial \eta}\left(C_{\xi} \sigma_{\eta \xi}\right)+\sigma_{\xi \eta} \frac{\partial C_{\xi}}{\partial \eta}-\sigma_{\eta \eta} \frac{\partial C_{\eta}}{\partial \xi}\right] \\
\frac{\partial v}{\partial t}+\frac{1}{C_{\xi} C_{\eta}}\left[\frac{\partial}{\partial \xi}\left(C_{\eta} v u\right)+\frac{\partial}{\partial \eta}\left(C_{\xi} v^{2}\right)+u v \frac{\partial C_{\eta}}{\partial \xi}-u^{2} \frac{\partial C_{\xi}}{\partial \eta}\right]=-g \frac{1}{C_{\eta}} \frac{\partial Z}{\partial \eta}-f u \\
-\frac{v \sqrt{u^{2}+v^{2} n^{2}}}{h^{4 / 3}} g+\frac{1}{C_{\xi} C_{\eta}}\left[\frac{\partial}{\partial \xi}\left(C_{\eta} \sigma_{\xi \eta}\right)+\frac{\partial}{\partial \eta}\left(C_{\xi} \sigma_{\eta \eta}\right)+\sigma_{\eta \xi} \frac{\partial C_{\eta}}{\partial \xi}-\sigma_{\xi \xi} \frac{\partial C_{\xi}}{\partial \eta}\right]
\end{gathered}
$$

where $\xi$ and $\eta$ represent two orthogonal curvilinear coordinates in the orthogonal curvilinear coordinate system; $u$ and $v$ represent the flow velocities in the $\xi$ and $\eta$ directions, respectively; $h$ represents the water depth; $Z$ represents the water level; $f$ represents the Coriolis coefficient and can be calculated as $f=\Omega_{d} \sin \phi$ where $\Omega_{d}$ is the rotational angular velocity of the earth and $\phi$ is the latitude; $n$ is the roughness coefficient; $v_{t}$ represents the coefficient of turbulent viscosity and is calculated using $V t=\alpha U * h$, where $\alpha$ is a constant $(\alpha=0.25 \sim 1.0)$ and $U_{*}$ is the frictional velocity; $C_{\xi}$ and $C_{\eta}$ 
represent the Lamé coefficients in the orthogonal curvilinear coordinate system, expressions of which are $C_{\xi}=\sqrt{x_{\xi}^{2}+y \xi^{2}}$ and $C_{\eta}=\sqrt{x_{\eta}^{2}+y_{\eta}^{2}}$, respectively; and $\sigma_{\xi \xi}, \sigma_{\xi \eta}, \sigma_{\eta \xi}$ and $\sigma_{\eta \eta}$ represent the turbulence stresses, which are calculated as follows (Equations (8)-(10)):

$$
\begin{gathered}
\sigma_{\xi \xi}=2 v_{t}\left[\frac{1}{C_{\xi}} \frac{\partial u}{\partial \xi}+\frac{v}{C_{\xi} C_{\eta}} \frac{\partial C_{\xi}}{\partial \eta}\right] \\
\sigma_{\eta \eta}=2 v_{t}\left[\frac{1}{C_{\eta}} \frac{\partial v}{\partial \eta}+\frac{u}{C_{\xi} C_{\eta}} \frac{\partial C_{\eta}}{\partial \xi}\right] \\
\sigma_{\xi \eta}=\sigma_{\eta \xi}=2 v_{t}\left[\frac{C_{\eta}}{C_{\xi}} \frac{\partial}{\partial \xi}\left(\frac{v}{C_{\eta}}\right)+\frac{C_{\xi}}{C_{\eta}} \frac{\partial}{\partial \eta}\left(\frac{u}{C_{\xi}}\right)\right]
\end{gathered}
$$

Depending on numerical discretization strategies, the finite volume methods (FVM) were introduced in our study to obtain the numerical solutions [5,9]. To avoid the formation of a jagged velocity field and pressure field, the staggered mesh method was introduced. In addition, the SIMPLEC algorithm and under-relaxation technology were used to complete the correction of the velocity equation and the depth equation and further accelerate the convergence of the correction equation $[5,37]$.

In this study, a method based on the empirical formulas [38,39] was introduced to estimate the Manning roughness coefficients, and the cross-sectional flow resistance was corrected [2,40].

\subsection{Spatio-temporal Computation Framework}

Floods are a common process on the Earth's surface and have apparent spatio-temporal characteristics. Multiple factors are often involved in spatial analyses of river water and dynamic simulations of flood risk. Spatio-temporal big data have laid an important foundation for flood monitoring, dynamic simulations, and risk assessments [36].

The spatio-temporal GIS framework is an important aspect of spatial information science. Hydrodynamic models are an important component of the study of the hydraulics. The seamless integration of spatio-temporal GIS and hydrodynamic models involves a crossover study of the two subjects [36]. Due to the complexity of hydrodynamic models, model researchers often emphasize studies on model parameters, model applicability, and model accuracy and develop separate software tools for model calculations. The preparation of data, the calculation process, and the output results of models create their own system, without in-depth docking with application scenarios. Most model outputs are 2D tables with poor visualization effects [2]. Spatio-temporal GIS has strong capabilities in data acquisition, management, storage, analysis, calculation, and multidimensional visualization. Calculations of hydrodynamic models are embedded into the spatio-temporal GIS, and seamless integration is performed on the data flow, calculations, outputs and storage, and visualization [15]. Spatio-temporal GIS provides DEM, rainfall, and other types of data inputs about the river landforms and flood detention areas that are used to calculate the hydrodynamic model, as well as calculation resources and storage of the model calculation results. Multidimensional dynamic visualizations are performed for the model results using the visualization capability of the spatio-temporal GIS, thus realizing the seamless integration of the spatio-temporal GIS with the hydrodynamic model, as shown in Figure 3. 


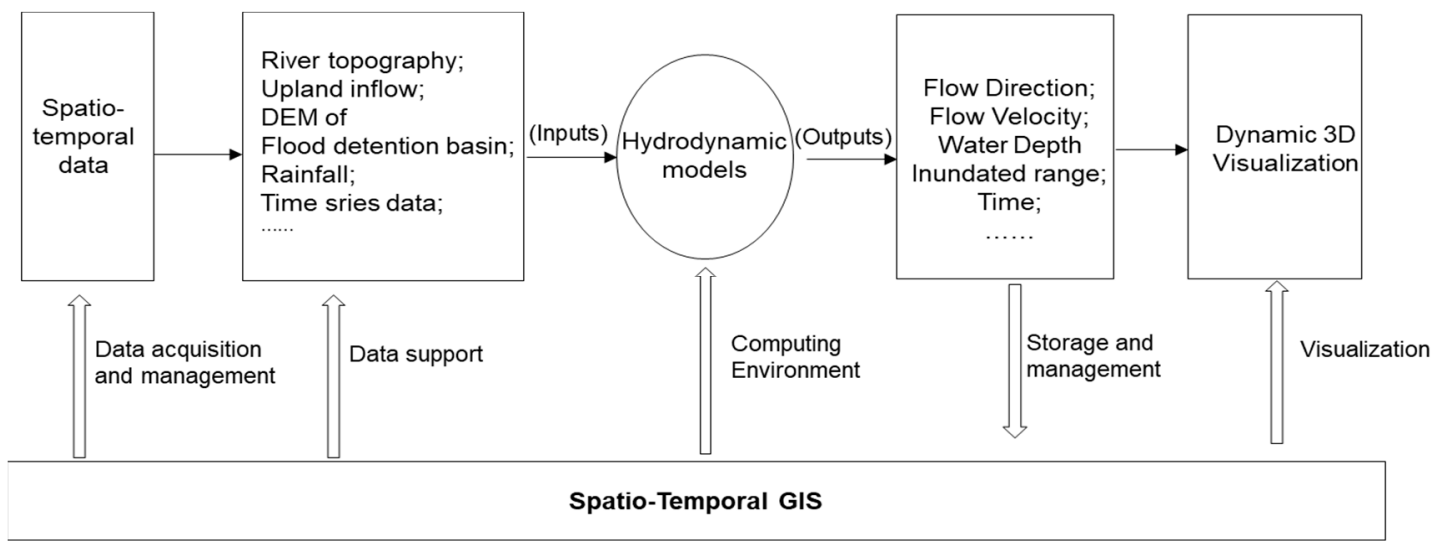

Figure 3. Conceptual model of the spatio-temporal computation framework. GIS, Geographic Information System.

The logical framework for the seamless integration of the spatio-temporal GIS with the hydrodynamic model is shown in Figure 4. It is based on service-oriented architecture (SOA) and is divided into the hardware layer, the data layer, the platform layer, the service layer, and the application layer, from bottom to top. The data layer includes static 3D scene data, IoT sensed and socioeconomic data, and spatio-temporal flood risk data. The static 3D scene data mainly include DOMs acquired by oblique photography-based 3D modeling, 1:2000 DEMs, 3DM data, river body data, and 3D model data of hydraulic engineering facilities. The IoT perception data include time series data acquired by sensing equipment at the hydrometrical station and the precipitation station. The spatio-temporal flood risk data include the flow velocity, flow direction, discharge, water depth, and inundated area at different sections, locations, and times, which are the outputs of the hydrodynamic model. The core of the platform layer is a spatio-temporal GIS, which is based on a digital earth platform developed by the authors. The platform layer connects the preceding and the following procedures, performs data management for the following procedures, and provides service integration, calculations, and data for the preceding procedures [41,42]. The service layer encapsulates core modules or functions for services, which allow the application and operational system developers to focus on the business process and user demands and simplifies the development workload in the application layer. The service and application layers are loosely coupled to enhance system flexibility and scalability $[43,44]$. The application layer performs a dynamic visual simulation of the flood risk for decision support, acting as an interface for the conversion of data to information and knowledge.

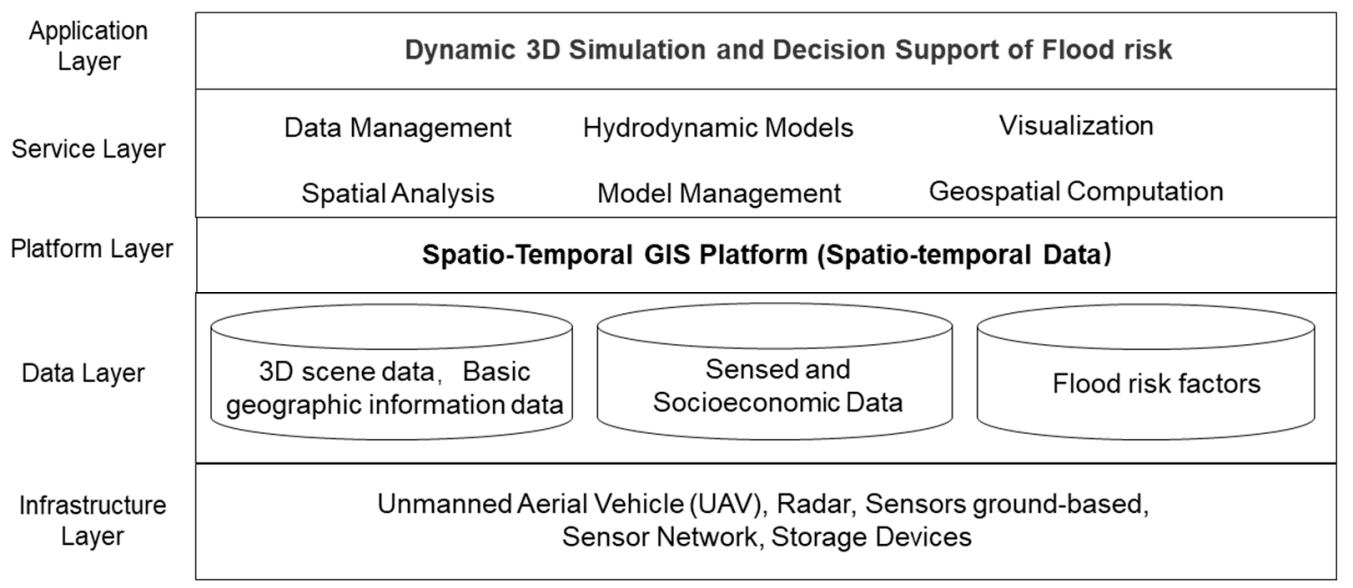

Figure 4. Logical framework for the integration of spatio-temporal GIS with hydrodynamic models. 


\section{Case Study}

\subsection{The Study Area}

As the largest reservoir in the Shandong Province, the Xiashan Reservoir is in the middle reach of the Weihe River (Figure 5). The total watershed area of the upstream and downstream reaches is up to $107.7 \mathrm{~km}^{2}$. It has a total capacity of 1.405 billion $\mathrm{m}^{3}$. The reservoir area is large and includes 4 counties and cities, 11 townships, and 97 immigrant villages [45]. The reservoir has been in service since September 1960. It is a large water conservancy project that integrates flood control, irrigation, power generation, aquaculture, urban and industrial water supply, and other comprehensive utilizations. The designed irrigation area of the reservoir is $1020 \mathrm{~km}^{2}$ and the effective irrigation area is $693 \mathrm{~km}^{2}$. The main dam of the Xiashan Reservoir is $2680 \mathrm{~m}$ long. The average annual rainfall in the reservoir area is $615.3 \mathrm{~mm}$, approximately $80 \%$ of which is concentrated in the period from June to September. The study area includes the Xiashan Reservoir, $70 \mathrm{~km}$ from the upstream and downstream river channel of the Weihe River, and the flood detention area downstream of the reservoir, with a total area of $175 \mathrm{~km}^{2}$.

\subsection{Construction of a Spatio-Temporal Database}

Spatio-temporal data include basic spatial data, perception data, socioeconomic data, and spatiotemporal data of flood risk factors. The 3D spatial data of the reservoir area and the 70-km river channel upstream and downstream stretch of the Weihe River were acquired by oblique photography-based 3D modeling, including a DOM with a resolution of $0.1 \mathrm{~m}$, a 3DM, and a 1:2000 DEM. The perception data are mainly the time series data at the precipitation station and the hydrometrical station. The demographic and socioeconomic data mainly include data on road traffic, demographic data from administrative regions at all levels, the locations of administrative regions, and the spatial positions and associated attributes of schools, hospitals, public security organizations, factories, and other institutes. The spatio-temporal data contents are shown in Table 4.

\subsection{Dynamic Visual Simulation System for Flood Risk}

By referring to Section 2.3 ("Spatio-temporal Computation Framework") (Figure 4) and using digital earth as the engine, a dynamic visual simulation system for the flood risk at the Xiashan Reservoir was established to complete the seamless integration of the spatio-temporal GIS with the hydrodynamic model. The system functions, as shown in Figure 6, mainly include such modules as data management, data query, model calculation, flood process simulation, and visual decision making. The spatio-temporal GIS module provides functions such as spatio-temporal data processing, visualization, spatio-temporal analysis, and spatial data management. The "Calculation of Hydrodynamic Model" module supports computing environment settings such as model selection, parameter input, and flood type selection. The "Simulation and Visualization of Hydrodynamic Model" module simulates the evolution process of floods and performs 3D visualization for the inundated area, water depth, flow velocity, flow direction, and so on. The "Query and Statistics" module can analyze and visualize the perception data from the precipitation and hydrometrical stations by time frame. The system can access different types of sensor data and other business system data through the Integration Interface. Based on the system, the hydrodynamic data can be input, calculated, and visually embedded into the flood process simulation and the flood control and emergency management services to improve the timeliness, scientific reliability, and visualization effect of the flood risk simulations [46]. 


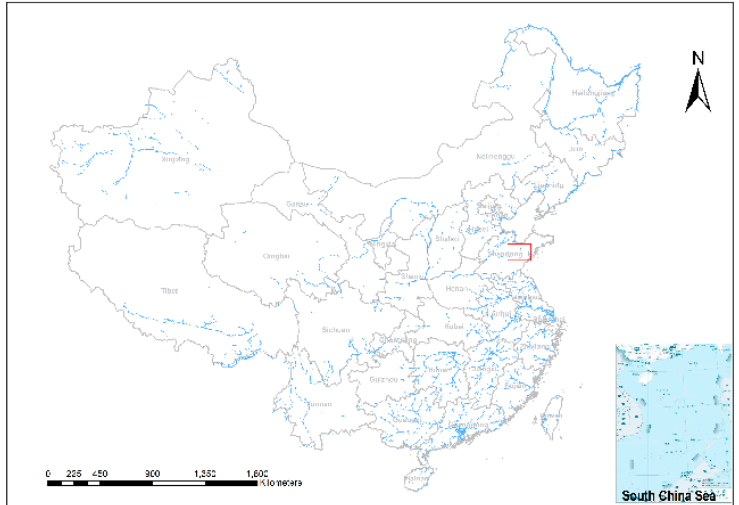

(a)

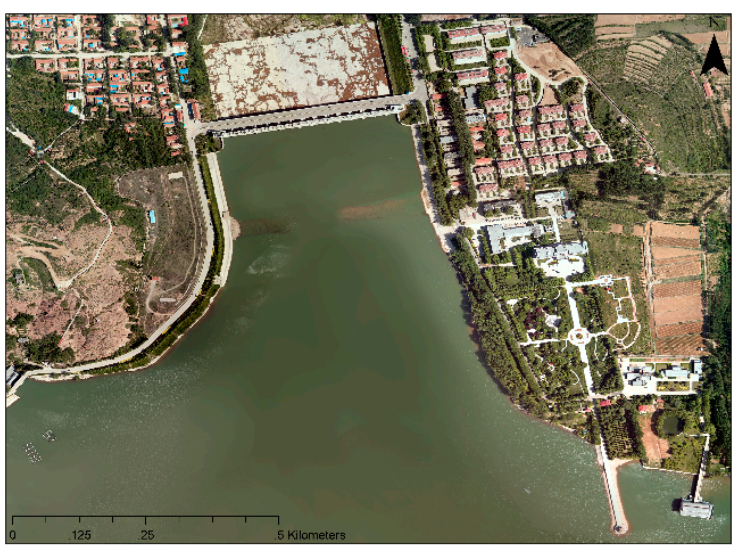

(b)

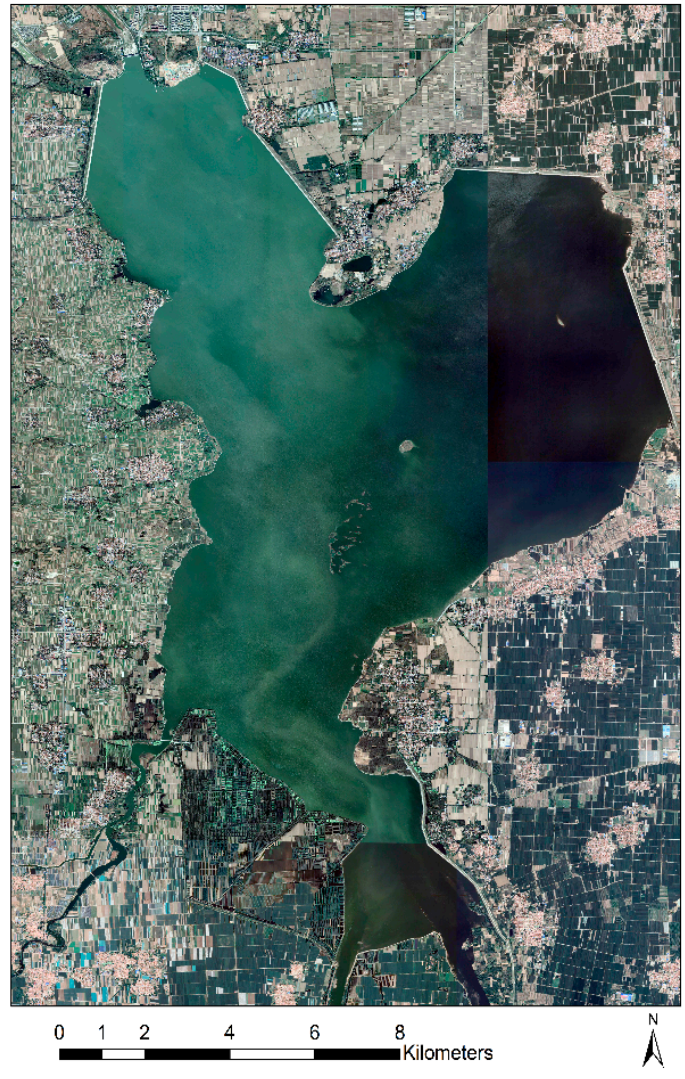

(c)

Figure 5. Location of the Xiashan Reservoir: (a) The location of the Xiashan Reservoir in China; (b) the Xiashan Reservoir Dam; (c) the layout of the Xiashan Reservoir.

The system adopts a Brower/Server architecture and releases a GIS service as a Web Service [47]. It integrates the data from the rainfall monitoring system, hydrologic monitoring system, video monitoring system, meteorological system, land geological disaster system, and other operational systems into a unified spatio-temporal database. Under the unified spatio-temporal calculation framework, flood risk simulation, hydrological data query statistics, and other operations are packaged to complete the seamless integration of the data flow, operation flow, and system functions. The system architecture is shown in Figure 7.

Table 4. Relevant parameters of spatio-temporal data.

\begin{tabular}{|c|c|c|c|}
\hline Number & Data Type & Index & Data Sources \\
\hline 1 & $\begin{array}{l}\text { Digital elevation model (DEM) } \\
\text { of the topographic data of the } \\
\text { river channel }\end{array}$ & 1:2000 & \multirow{5}{*}{$\begin{array}{l}\text { Oblique } \\
\text { photography-based } \\
\text { 3D modeling }\end{array}$} \\
\hline 2 & DEM of the flood detention area & $1: 2000$ & \\
\hline 3 & DEM of the dam area & $1: 2000$ & \\
\hline 4 & Digital orthophoto map & Resolution: $0.1 \mathrm{~m}$ & \\
\hline 5 & 3D scene model (3DM) & 3DM for the core area & \\
\hline 6 & Images of the peripheral area & Resolution: $2.5 \mathrm{~m}$ & $\begin{array}{c}\text { Historical } \\
\text { satellite images }\end{array}$ \\
\hline 7 & DEM of the peripheral area & $1: 10,000$ & $\begin{array}{c}\text { Basic scale } \\
\text { topographic map }\end{array}$ \\
\hline
\end{tabular}


Table 4. Cont.

\begin{tabular}{|c|c|c|c|}
\hline Number & Data Type & Index & Data Sources \\
\hline 8 & $\begin{array}{l}\text { 3D models of the hydraulic } \\
\text { engineering facilities }\end{array}$ & $\begin{array}{l}\text { Hydrometrical station and } \\
\text { precipitation station, etc. }\end{array}$ & \\
\hline 9 & Road traffic & $1: 10,000$ roads & $\begin{array}{c}\text { Basic scale } \\
\text { topographic map }\end{array}$ \\
\hline 10 & Population & $\begin{array}{l}\text { Populations in counties, } \\
\text { prefectures, towns, } \\
\text { townships, and villages }\end{array}$ & Statistical data \\
\hline 11 & Other social data & $\begin{array}{l}\text { Positions of counties, } \\
\text { prefectures, towns, } \\
\text { townships, and villages }\end{array}$ & $\begin{array}{c}\text { Basic scale } \\
\text { topographic map }\end{array}$ \\
\hline 12 & Perception series data & $\begin{array}{l}\text { Rainfall, water level, } \\
\text { forecasted rainfall, etc. }\end{array}$ & $\begin{array}{l}\text { Internet of Things } \\
\text { (IoT) perception }\end{array}$ \\
\hline \multirow[t]{7}{*}{13} & Data of flood risk factors & $\begin{array}{l}\text { Flow velocity, flow } \\
\text { direction, water depth, } \\
\text { and inundated area, etc. }\end{array}$ & Model calculation \\
\hline & & Spatio-Temporal GIS & \\
\hline & & $\begin{array}{c}\text { Calculation of } \\
\text { Hydrodynamic model }\end{array}$ & \\
\hline & $\begin{array}{l}\text { Dynamic Visual } \\
\text { Simulation System }\end{array}$ & $\begin{array}{c}\text { Simulation and Visualization } \\
\text { of Hydrodynamic model }\end{array}$ & \\
\hline & $\begin{array}{l}\text { for Flood Risk of } \\
\text { Xiashan Reservoir }\end{array}$ & Query and Statistics & \\
\hline & & Integration Interface & \\
\hline & & System Management & \\
\hline
\end{tabular}

Figure 6. Functional modules of the dynamic visual simulation system for the flood risk of the Xiashan Reservoir.

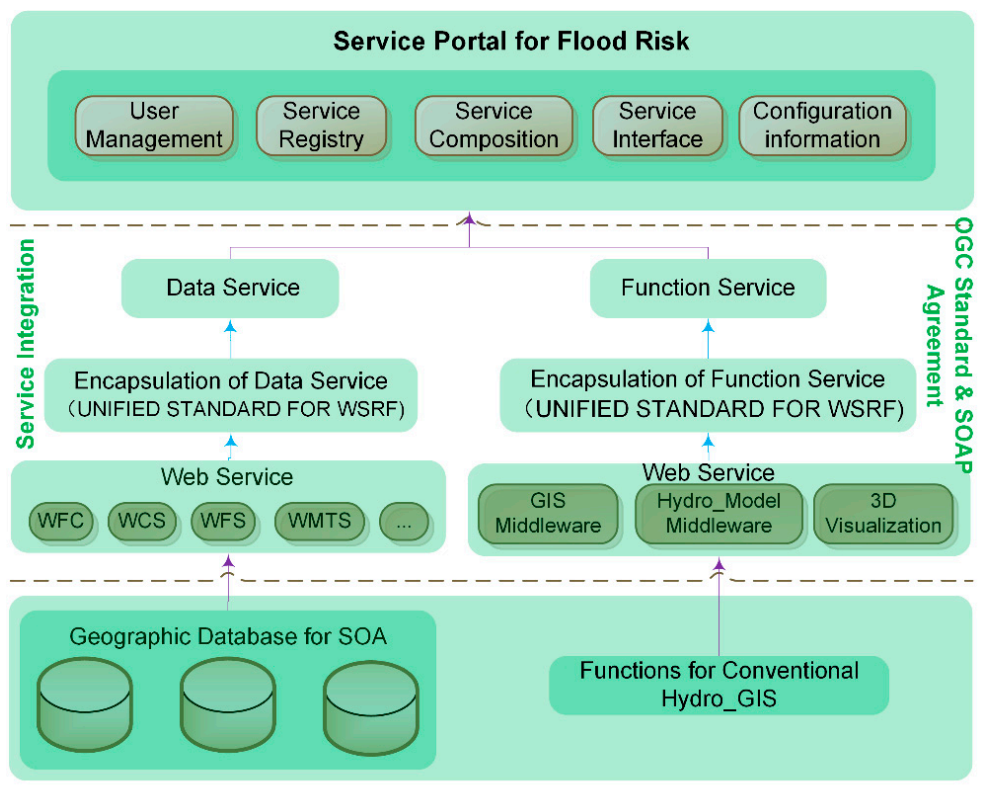

Figure 7. System functions and service architecture based on service-oriented architecture (SOA). 


\section{Results}

\subsection{Three-Dimensional Visualization of the Study Area}

According to the methods in Section 2.1, a 3D visual simulation of the watershed, reservoir area, river, and hydraulic engineering facilities was realized by organizing and visualizing the spatial data in a spatio-temporal GIS framework. The 3D visualization of the study area is shown in Figure 8.

The system can quickly retrieve information about the ecological environmental system of the reservoir, river channel, hydraulic engineering facilities, and the peripheral area. Relying on the strong spatial analyses and visualization abilities of spatio-temporal GIS, the integration of the dynamic evaluation, visualization, and decision support for flood risk is greatly improved.

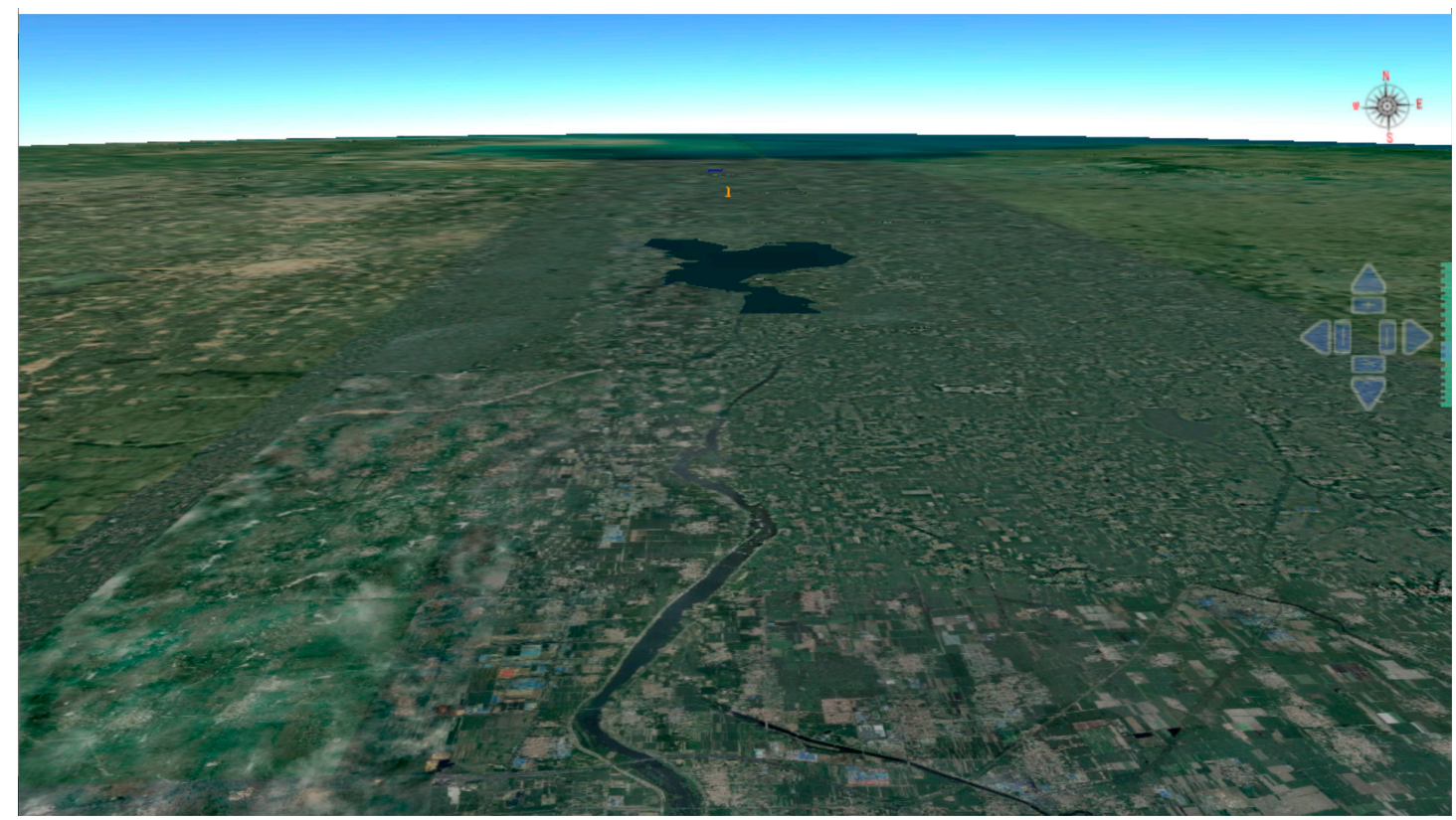

(a)

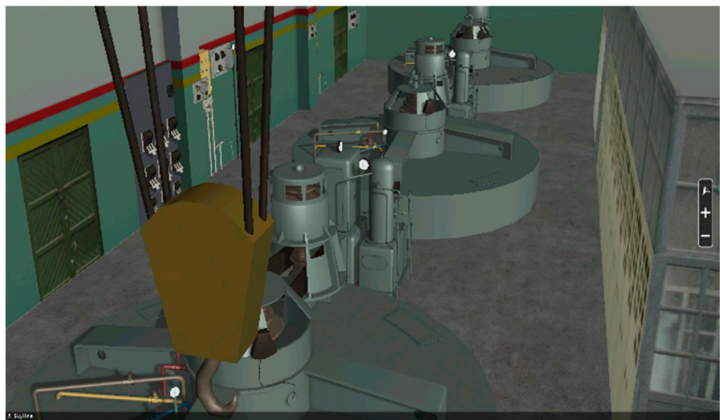

(b)

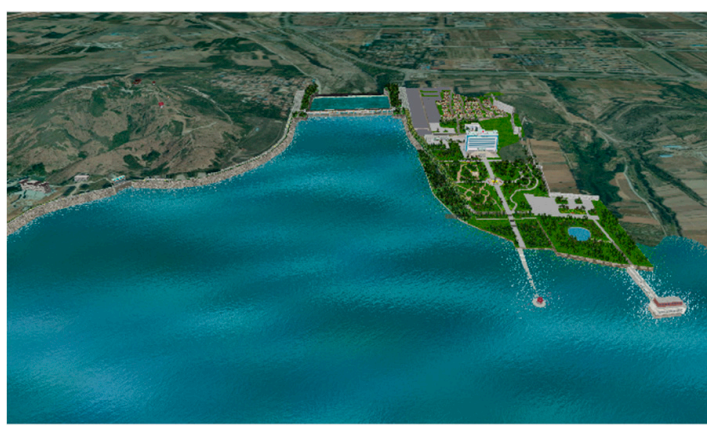

(c)

Figure 8. 3D visualization of the study area: (a) A bird's-eye view of the Xiashan reservoir and Weihe river; (b) A 3D view of the indoor facilities; (c) A 3D view of the administration agency.

\subsection{Visual Simulation of $1 D$ and $2 D$ Flood Routing in the River Channel}

By using the 1D and 2D hydrodynamic models embedded in the system, values for the flooding in the river channels upstream and downstream of the Xiashan Reservoir were calculated, and the 3D routing simulation was eventually realized. The system automatically calculated the flood process in the river channels upstream and downstream of the Xiashan Reservoir according to the user-supplied input parameters and the system data. The calculation results include flood flow hydrographs of the 
channel upstream of the reservoir and its statistical flood characteristics (including time, water volume, and the highest water level of the river channel) (Figure 9).

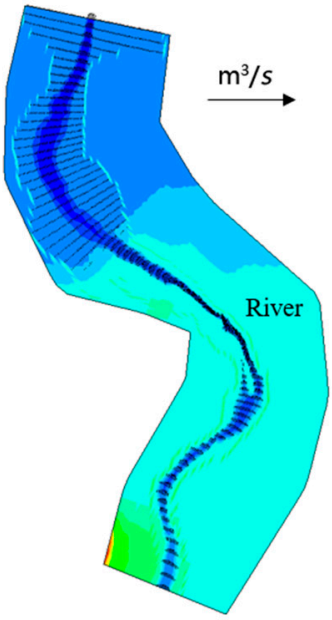

Flow Field: $\mathrm{Q}=694.6 \mathrm{~m}^{3} / \mathrm{s}$

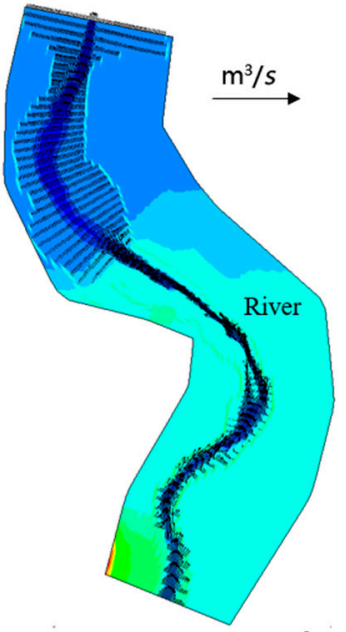

Flow Field: $\mathrm{Q}=3,883.93 \mathrm{~m}^{3} / \mathrm{s}$

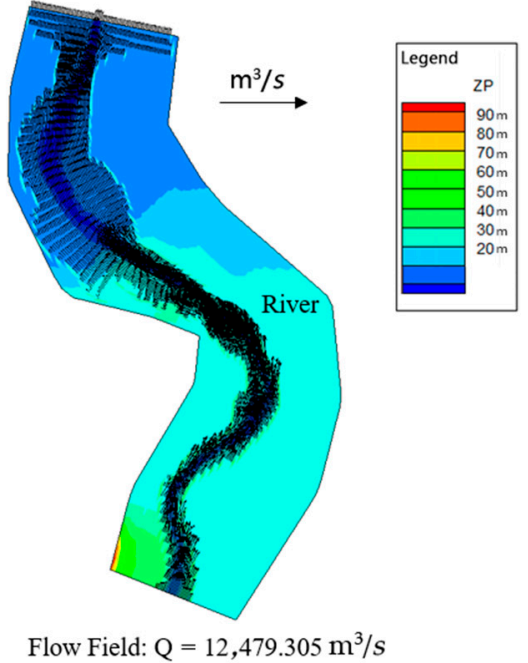

Flow Field: $\mathrm{Q}=12,479.305 \mathrm{~m}^{3} / \mathrm{s}$

Figure 9. Calculation results of the 2D flow mathematical model of the river channel downstream of the Xiashan Reservoir (river channel).

We dynamically showed the inundated area based on the flood and water level at any point on the river channel for a specific time period using time as the axis. A 3D visual simulation analysis of the evolution of the in-channel water level was produced by using the visualizing function of the system (Figure 10).
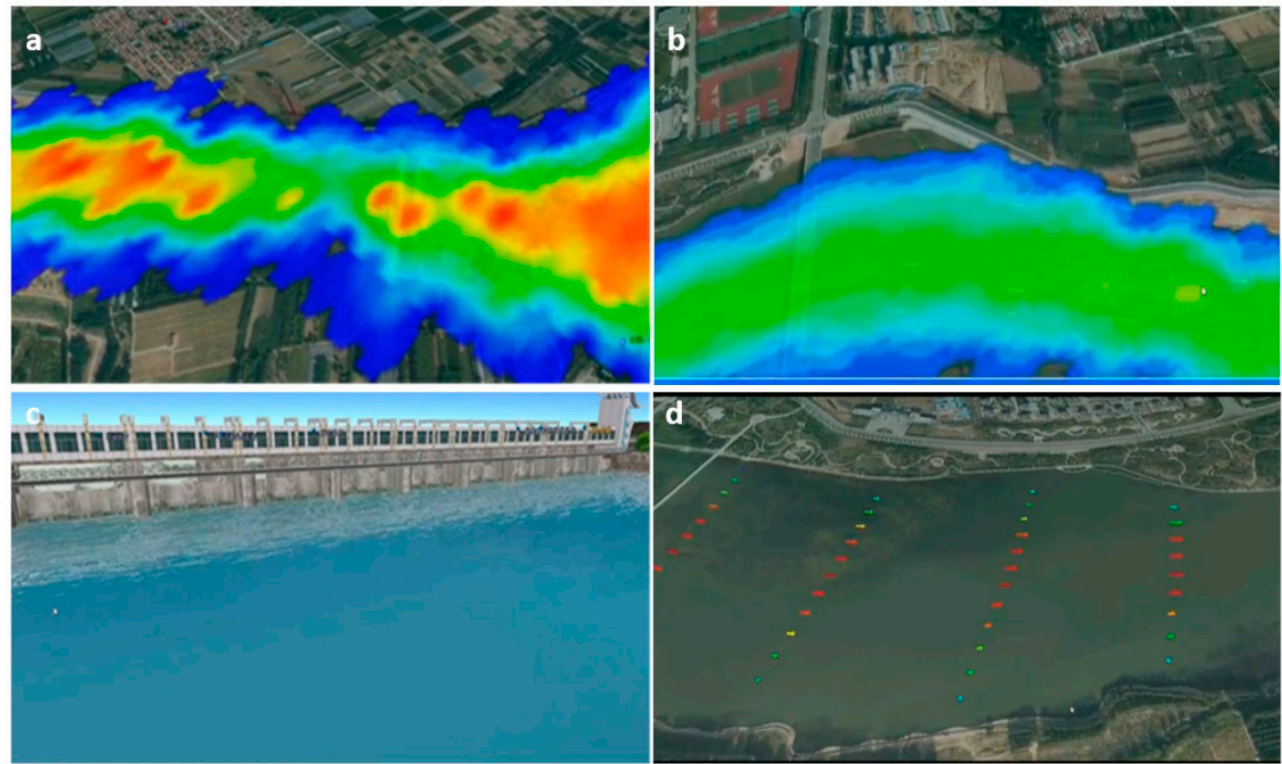

Figure 10. 3D simulation of two-dimensional (2D) flow in the downstream river channel. (a,b) The area of flood submergence and the color from red to blue represents the water depth from deep to shallow, respectively; (c) the dynamic monitoring and display of the water level in front of the reservoir dam during flood discharge; (d) the dynamic visualization simulation of one-dimensional (1D) and 2D hydrodynamic models in the river channels upstream and downstream of the reservoir, where the length of the arrows represents the flow velocity, the color of the arrows from red to green represents the water depth from deep to shallow, respectively, and the direction of the arrows represents the flow direction. 


\subsection{Visual Flood Control Dispatching for the Xiashan Reservoir}

Based on the high-accuracy 3D scene data in the system and with time as the system axis, the model calculation results were dynamically simulated and shown, including the change in the water level in front of the reservoir dam over time for a given flood or runoff event. The degree of backwater in the reservoir area and the inundation level and its dynamic routing were simulated under the designated dispatching scheme (Figure 11).

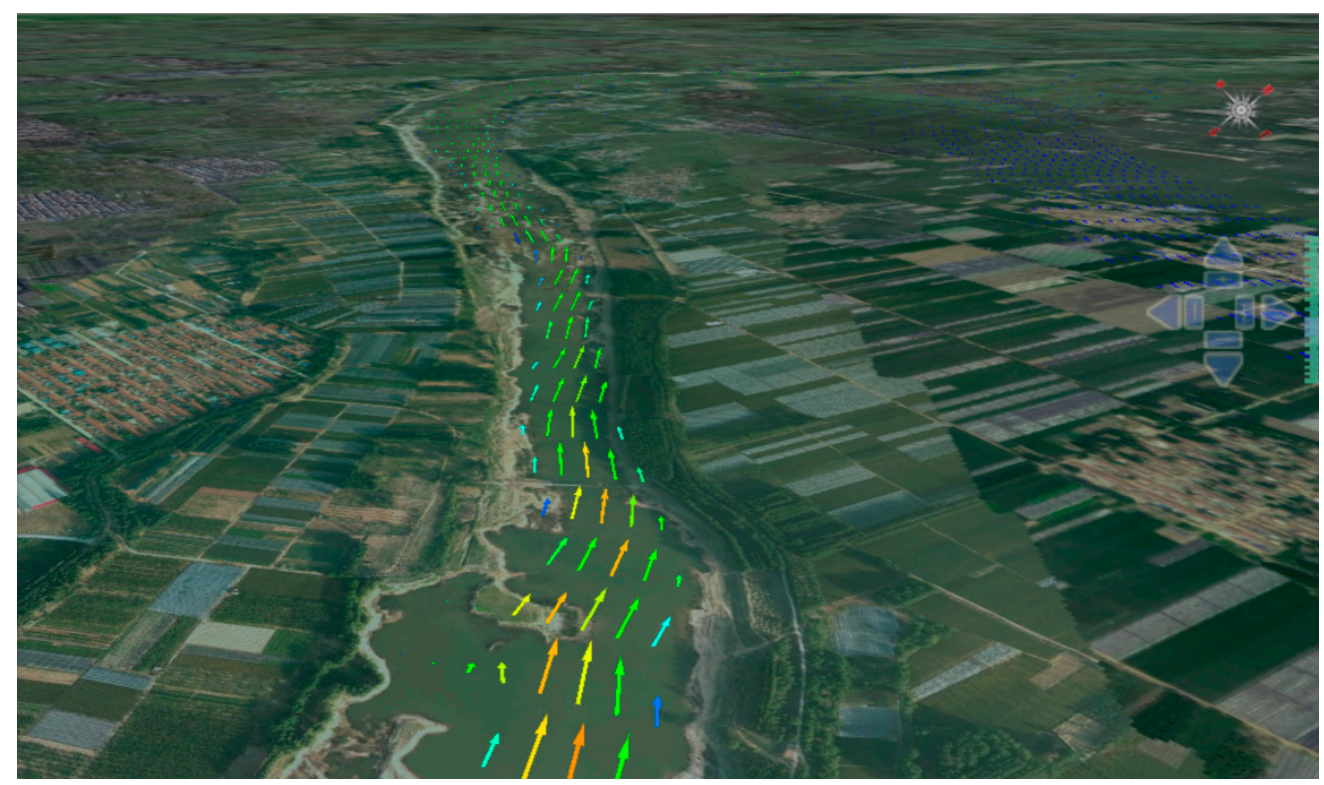

Figure 11. 3D demonstration of the flood control dispatching process of the Xiashan Reservoir. (The arrow direction indicates the flow direction. The longer the arrow, the higher the flowrate. Color is used to show the depth of the water. From green, blue, yellow to red, the darker the color, the greater the water depth.)

This function module can perform reservoir flood control calculations based on a given (or forecasted) flood or runoff event and presents the changes in the reservoir water levels and discharged volumes. It also calculates the amount of backwater in the reservoir area, the inundation level, the discharged flow, the flow velocity, and the water level change under the dispatching scheme, in combination with the 1D hydrodynamic calculation model and the discharge calculation model of the spillway structure of the dam. The integrated calculation and dynamic visual simulation processes can improve the decision-making efficiency of flood control dispatching consultations and flood dispatching levels and minimize the impacts of flood risk [48].

\subsection{Visual Simulation of Dam Break}

Once the reservoir dam breaks, a destructive flood will form, causing severe casualties and loss of social properties on the downstream side, which would significantly influence social and economic development in the downstream area of the reservoir [32]. The dam-break flood analysis mainly involves calculating the flood process at the dam site and in the downstream area, including the flow and water-level hydrographs at the dam site and the discharge, water level, flow velocity, and peak arrival time in the downstream flood routing.

In addition, we also calculated the downstream flood fields at the moment of main dam break at $\mathrm{T}=10 \mathrm{~s}, \mathrm{~T}=0.5 \mathrm{~h}, \mathrm{~T}=1.0 \mathrm{~h}$, and $\mathrm{T}=1.5 \mathrm{~h}$ (Figure 12). The figure shows that because the lateral length of the main dam is much greater than the width of the spillway, the flow velocity at the moment of main dam breakage $(t=10 \mathrm{~s})$ is lower than it is at the moment of spillway breakage, with a maximum 
flow velocity of $16.77 \mathrm{~m} / \mathrm{s}$. The flood at the moment of main dam breakage covers a wider downstream inundated area compared with that at the moment of spillway breakage.

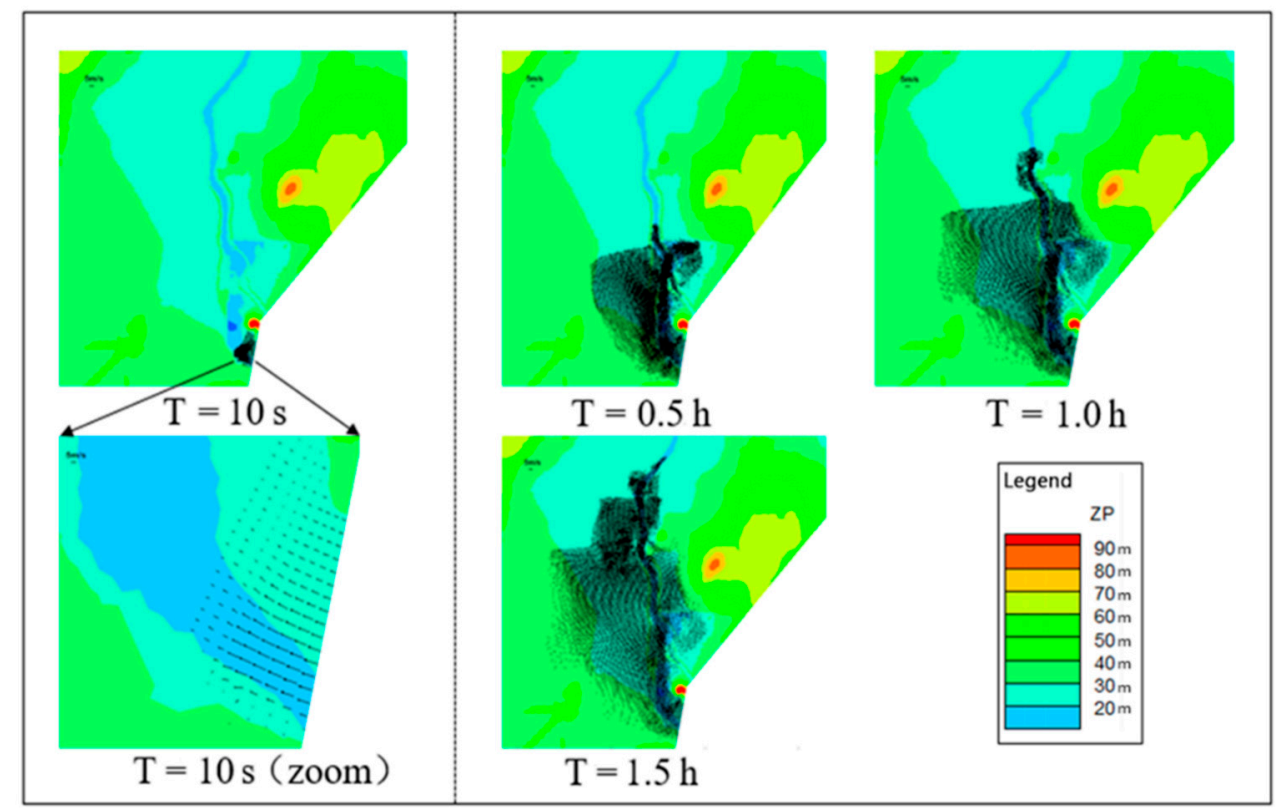

Figure 12. Calculation results of the main dam break.

Based on the DEM data from the middle and lower reaches of the system and on the 1D and 2D river channel hydrodynamic models embedded in the system, we dynamically simulated the downstream flood process of the reservoir after a dam break (Figure 13), including calculating the inundated area at different times and other flood characteristics, such as the water depth, flow velocity, and flow direction at any point.

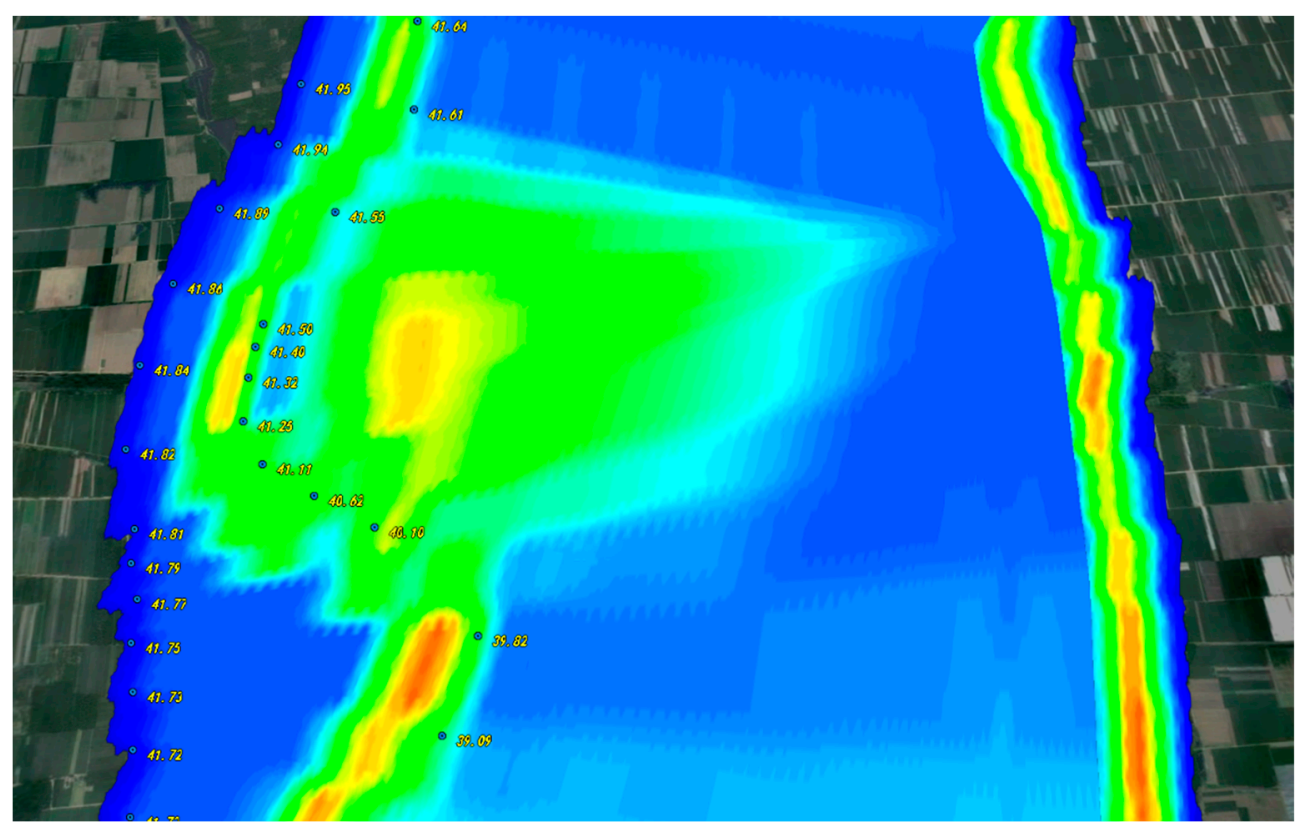

Figure 13. 3D simulation of dam-break flow. (There are two rivers in this figure. After the dam broke, the area between the two rivers was also inundated.) 


\subsection{Verification of Hydrodynamic Model and Sensitivity Analysis}

According to the water level and discharge data of seven typical available sections, we verified the 1D and 2D hydrodynamic models. Figure 14 shows a comparison between the calculated values of the water levels during floods at different design frequencies and the measured data from seven typical sections.
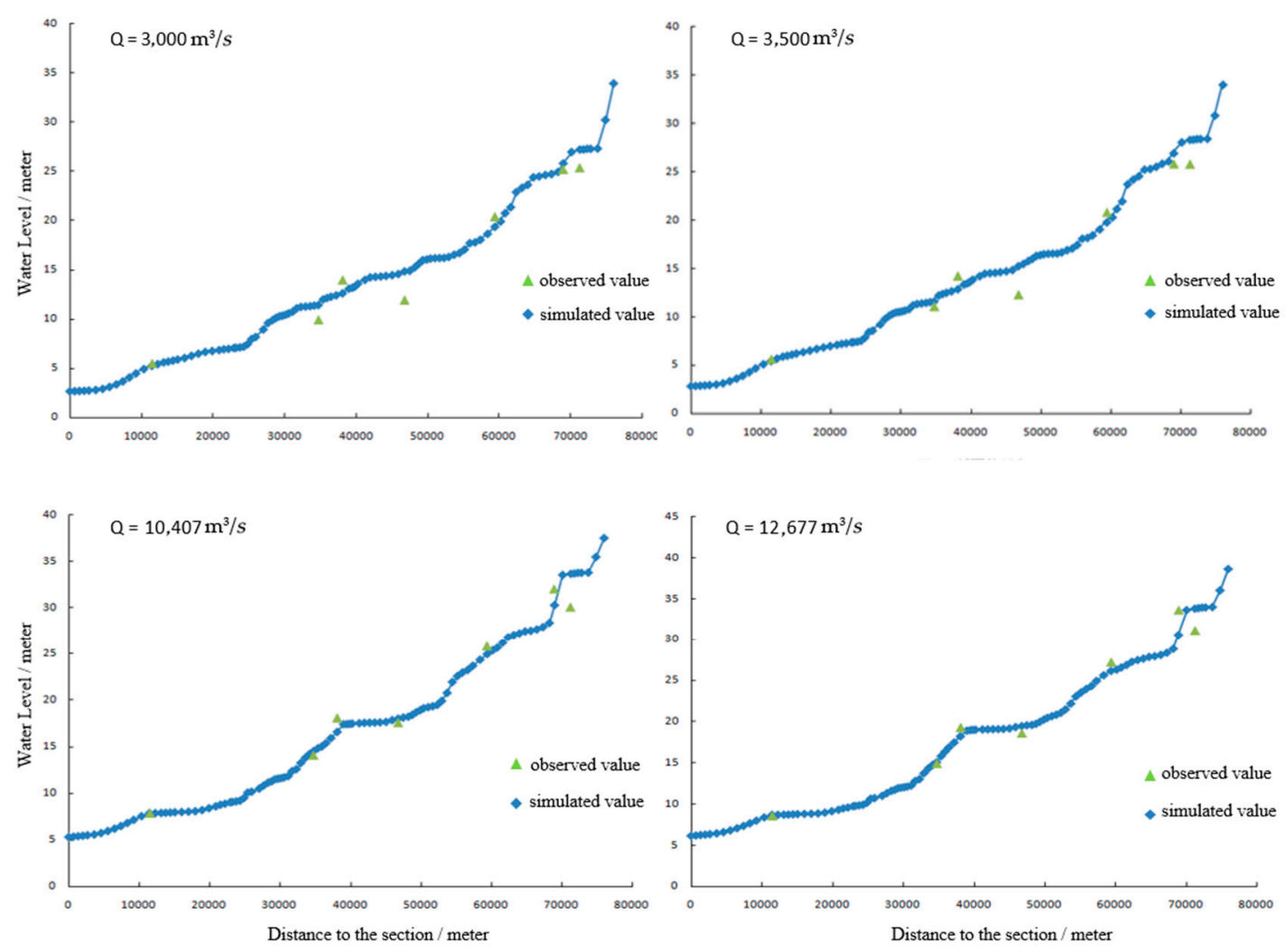

Figure 14. Preliminary verification of the mathematical model of flow in the river channel downstream of the Xiashan Reservoir.

As seen in Figure 14, under the designed discharge, the calculated value of the model is consistent with the measured data, indicating that the established mathematical model can largely simulate the dynamic pattern of water flow of the river channel downstream of the Xiashan Reservoir.

\section{Discussion}

Hydrodynamic models are fundamental to flood quantitative simulations. The accuracy and reliability of these computations are closely related to the availability, timeliness, and scale or resolution of data [5]. Hydrodynamic models are highly specialized; therefore, visualization and intuitive representations of their results are very important for scientific decision making. The integration of hydrodynamic model computations and emergency management is one of the important factors for improving the efficiency of flood emergency administration [4]. This paper offers methods for quickly establishing a spatio-temporal GIS framework for flood risk simulations and seamlessly integrating spatio-temporal GIS and hydrodynamic models. These methods can effectively solve the problems of data availability, visualization, and integration of hydrodynamic models, which will improve flood risk simulations and emergency administration.

The method proposed in this paper is used to quickly construct flood risk simulation spatio-temporal GIS, which provides up-to-date data for hydrodynamic model computations. Basic geo-information data, such as topography, are the basis of hydrodynamic model computations [5]. In practice, hydrodynamic model computations are often affected by the poor availability of basic data, poor timeliness, and low 
resolution of data. The following factors will lead to the failure of hydrodynamic model computations or the poor reliability and accuracy of computation results: (a) Difficulty in obtaining basic data for various reasons; (b) poor timeliness of basic data; and (c) low-resolution basic data. In this paper, tilt photogrammetry, three-dimensional modeling, and a digital earth platform are used to rapidly construct a spatio-temporal GIS framework, which provides up-to-date and high-resolution basic data for hydrodynamic model computations. This framework also includes increased storage and multi-dimension visualization.

The integrated framework realizes seamless integration of data, business information, and system functions contained within spatio-temporal GIS and the hydrodynamic model. It promotes the application of flood risk simulation results in emergency administration, which will improve the efficiency of decision making. In most realistic applications, the data acquisition system, the hydrodynamic model computation system, the visualization system, and the business management system are individual systems [18]. Therefore, interoperability among these systems is usually not very good, which affects the efficiency of emergency administration of flood disasters. The integration framework described in this paper integrates data collection, model computation, dynamic visualization, and emergency administration, which enables data flow and business processes to flow through a unified platform. In practice, this will shorten decision-making time in emergency management. Based on this framework, a dynamic visual simulation platform for the flood risk at Xiashan Reservoir was established, which could be used to conduct three-dimensional dynamic simulations of flood evolution The platform intuitively displays the variations in the inundation range over time and the changes in the flood velocity, flow direction, and flow discharge over time three-dimensionally, thus providing an easier way to understand flood evolution. The platform offers more scientific decision-support information for flood emergency management. Furthermore, the platform provides rich interfaces for the integration of monitoring systems, such as rainfall stations, hydrological stations, and so on. As a result, time series monitoring data can be connected to the platform in real time and can serve as input parameters for hydrodynamic models. In several cases, the static flood risk map will be created for specific rainfall and flood flow scenarios, such as a $100 \mathrm{~mm}$ rainfall event or a 50-year flood recurrence [49]. The map shows the inundation range, flood depth, etc. The methods proposed in this paper can be used to simulate flood processes under any rainfall or flow conditions, which can reflect changes in the flood inundation range as rainfall varies. Meanwhile, the simulation will be dynamically visualized in a three-dimensional way.

Flood risk simulations and emergency administration are complex systems, and their effectiveness and accuracy in realistic applications are influenced by many factors. Four research goals remain:

First, in common modeling practices, a physical model will be preferably constructed to assure the validity of the model outcomes [6]. This study focused on the construction of spatio-temporal GIS by using oblique photography and the seamless integration of spatio-temporal GIS and hydrodynamic models. Therefore, the physical models of Xiashan Reservoir and river channels were not constructed. The historical observation data from seven typical sections were used to verify the model (Section 4.5).

Second, the traditional hydrodynamic equations were used in the study. There are simplified equations in terms of the development of the hydrodynamic model [5]. The integration framework proposed in this study can integrate multiple hydrodynamic models. Therefore, hydrodynamic models themselves will not influence the integrated method proposed in this study. This paper focuses on the integration of three kinds of hydrodynamic models with spatio-temporal GIS. In the future, more hydrodynamic models will be integrated into the system and experiments will be conducted in other watersheds to improve the applicability of the method and the dynamic simulation system.

Third, from the view of model processes, the uncertainties include choice of model structures, model parameters, model inputs (e.g., channel geometry, floodplain), validation data, and land use change [5]. For this study, the main uncertainties were model structures, model inputs, and validation data. However, since the aim of the study was to propose a method for quickly establishing spatio-temporal GIS and put forward an integration framework, we did not quantify the uncertainties. The uncertainties will be identified, quantified, and represented in the future. 
In addition, the platform's current infrastructure does not employ a big data architecture. Using the dynamic simulation of flood risk, population, economy, and society data will be added, so that the quantitative assessment of the affected population, structures, and economy under different flood scenarios can be analyzed [23,50]. Different emergency plans will be provided to promote the intelligent development of emergency management of flood risk. MongDB and Spark will be used to reconstruct the underlying data, and then the operation efficiency of the whole system will be further improved [51].

\section{Conclusions}

In this study, a spatio-temporal computing framework for flood risk simulation is proposed. A seamless integration of spatio-temporal GIS and hydrodynamic models is realized for the data flow process, computing process, business process, and system functions. This framework can perform dynamic and visual simulations of flood evolution and can identify flood risk in three dimensions, greatly improving the efficiency of flood risk simulations and decision making. The method described in this paper can quickly establish a flood simulation in a spatio-temporal GIS framework, which can provide up-to-date and high-resolution basic data to compute hydrodynamic models. Taking Xiashan Reservoir as an example, a visual decision support platform for the flood risk of the Xiashan Reservoir was established; this platform seamlessly integrated spatio-temporal GIS with one-dimensional and two-dimensional hydrodynamic models. Using the hydrodynamic models, the platform can simulate and display the dynamic flood evolution in three dimensions. The results show changes in the flood factors, such as the inundation range, the cross-section velocity and flow, the water depth, etc., over time. The platform can provide three-dimensional flood simulations of various scenarios for flood emergency administration. In addition, it provides more intuitive and scientific decision support information than the individual hydrodynamic model system provides.

A three-dimensional representation of the study area was quickly established using tilt photogrammetry. A spatio-temporal database was established and included spatial data (DEM, three-dimensional model of water conservancy facilities, submerged areas, towns, villages, etc.) and temporal data (temporal data of flood factors, meteorological temporal data, temporal data of sensing networks such as hydrological stations, etc.). Based on the digital earth platform, a spatio-temporal GIS of the study area was constructed to support model computation, spatial analysis and multi-dimensional visualization. A three-dimensional representation was conducted of the water conservancy engineering facilities in the research area, such as the reservoirs, river bodies, dams, pump rooms, etc.

Flood risk was simulated dynamically and in three dimensions. Through a seamless integration of spatio-temporal GIS and hydrodynamic models, a flood risk dynamic simulation platform was established. The platform integrated parameters input, computation processes, visualization of the computation results and emergency management decision making. In the three-dimensional representation, the temporal evolution of the key flood factors, such as the flood inundation range, the inundation depth, the flow velocity and the flow direction, was displayed. A dynamic and visual assessment of flood risk was conducted and the spatio-temporal characteristics of human factors, geographical objects, events, and flood processes were comprehensively displayed.

With the advent of the Internet of Things, big data, cloud computing, artificial intelligence, and 5G technology, the frequency, varieties, and volume of flood risk monitoring data will increase. Accurate flood risk simulations and intelligent emergency management will be the focus of future research. The integrated framework and methods proposed in this paper have laid a foundation for these types of future studies.

Author Contributions: Conceptualization, Q.L.; methodology, Y.W. and Y.P.; software, Y.W. and F.P.; validation, Y.W.; formal analysis, Y.W. and F.P.; resources, Y.P. and Y.W.; data curation, H.L.; writing—original draft preparation, F.P.; writing-review and editing, Q.L., Y.W. and X.K.; visualization, Y.W. and F.P.; supervision, Y.P. and Q.L.; project administration, Y.P. and Y. W.

Funding: This research received no external funding.

Acknowledgments: The authors would like to express their gratitude to the project team. 
Conflicts of Interest: Yongxing Wu and Fei Peng contributed to the work equally and should be regarded as co-first authors. All authors declare no conflicts of interest.

\section{References}

1. Liu, N.; Fei, W. Analysis on the Basic Situation of Natural Disasters in 2018. Disaster Reduct. China 2019, 5, 14-17. (In Chinese)

2. Mignot, E.; Li, X.; Dewals, B. Experimental modelling of urban flooding: A review. J. Hydrol. 2019, 568, 334-342. [CrossRef]

3. Teng, J.; Vaze, J.; Kim, S.; Dutta, D.; Jakeman, A.J.; Croke, B.F.W. Enhancing the Capability of a Simple, Computationally Efficient, Conceptual Flood Inundation Model in Hydrologically Complex Terrain. Water Resour. Manag. 2019, 33, 831-845. [CrossRef]

4. Dang, A.T.N.; Kumar, L. Application of remote sensing and GIS-based hydrological modelling for flood risk analysis: A case study of District 8, Ho Chi Minh city, Vietnam. Geomat. Nat. Hazards Risk 2017, 8, 1792-1811. [CrossRef]

5. Teng, J.; Jakeman, A.; Vaze, J.; Croke, B.; Dutta, D.; Kim, S. Flood inundation modelling: A review of methods, recent advances and uncertainty analysis. Environ. Model. Softw. 2017, 90, 201-216. [CrossRef]

6. Lai, J.-S.; Chang, W.-Y.; Chan, Y.-C.; Kang, S.-C.; Tan, Y.-C. Development of a 3D virtual environment for improving public participation: Case study-The Yuansantze Flood Diversion Works Project. Adv. Eng. Inform. 2011, 25, 208-223. [CrossRef]

7. Liu, X.J.; Zhong, D.H.; Tong, D.W.; Zhou, Z.Y.; Ao, X.F.; Li, W.Q. Dynamic visualisation of storm surge flood routing based on three-dimensional numerical simulation. J. Flood Risk Manag. 2018, 11, 729-749. [CrossRef]

8. Leskens, J.G.; Kehl, C.; Tutenel, T.; Kol, T.; De Haan, G.; Stelling, G.; Eisemann, E. An interactive simulation and visualization tool for flood analysis usable for practitioners. Mitig. Adapt. Strateg. Glob. Chang. 2017, 22, 307-324. [CrossRef]

9. Macchione, F.; Costabile, P.; Costanzo, C.; De Santis, R. Moving to 3-D flood hazard maps for enhancing risk communication. Environ. Model. Softw. 2019, 111, 510-522. [CrossRef]

10. Wang, J. Spatio-temporal big data and its application in smart city. Satell. Appl. 2017, 3, 10-17.

11. Wang, J.; Wu, F.; Guo, J.; Cheng, Y.; Chen, K. Challenges and opportunities of spatio-temporal big data. Sci. Surv. Mapp. 2017, 42, 1-7.

12. Lin, H.; You, L.; Hu, C.; Chen, M. Prospect of Geo-Knowledge Engineering in the Era of Spatio-Temporal Big Data. Geomat. Inf. Sci. Wuhan Univ. 2018, 43, 2205-2211.

13. Li, S.; Dragicevic, S.; Castro, F.A.; Sester, M.; Winter, S.; Coltekin, A.; Pettit, C.; Jiang, B.; Haworth, J.; Stein, A.; et al. Geospatial big data handling theory and methods: A review and research challenges. ISPRS J. Photogramm. Remote Sens. 2016, 115, 119-133. [CrossRef]

14. Hu, K.; Gui, Z.; Cheng, X.; Wu, H.; McClure, S.C. The Concept and Technologies of Quality of Geographic Information Service: Improving User Experience of GIServices in a Distributed Computing Environment. ISPRS Int. J. Geo Inf. 2019, 8, 118. [CrossRef]

15. Wang, S.; Zhong, Y.; Wang, E. An integrated GIS platform architecture for spatiotemporal big data. Future Gener. Comput. Syst. 2019, 94, 160-172. [CrossRef]

16. Lienert, C.; Weingartner, R.; Hurni, L. Real-Time Visualization in Operational Hydrology through Web-based Cartography. Cartogr. Geogr. Inf. Sci. 2009, 36, 45-58. [CrossRef]

17. Lee, J.; Kang, M. Geospatial Big Data: Challenges and Opportunities. Big Data Res. 2015, 2, 74-81. [CrossRef]

18. Ventura, B.; Vianello, A.; Frisinghelli, D.; Rossi, M.; Monsorno, R.; Costa, A. A Methodology for Heterogeneous Sensor Data Organization and Near Real-Time Data Sharing by Adopting OGC SWE Standards. ISPRS Int. J. Geo Inf. 2019, 8, 167. [CrossRef]

19. Söderholm, K.; Pihlajamäki, M.; Dubrovin, T.; Veijalainen, N.; Vehviläinen, B.; Marttunen, M. Collaborative Planning in Adaptive Flood Risk Management under Climate Change. Water Resour. Manag. 2018, 32, 1383-1397. [CrossRef]

20. Schumann, A. Flood Safety versus Remaining Risks - Options and Limitations of Probabilistic Concepts in Flood Management. Water Resour. Manag. 2017, 31, 3131-3145. [CrossRef]

21. Kourgialas, N.N.; Karatzas, G.P. Flood management and a GIS modelling method to assess flood-hazard areas-a case study. Hydrol. Sci. J. 2011, 56, 212-225. [CrossRef] 
22. Wang, Y.; Chen, A.S.; Fu, G.; Djordjević, S.; Zhang, C.; Savić, D.A. An integrated framework for high-resolution urban flood modelling considering multiple information sources and urban features. Environ. Model. Softw. 2018, 107, 85-95. [CrossRef]

23. Fang, Y.; Jawitz, J.W. The evolution of human population distance to water in the USA from 1790 to 2010. Nat. Commun. 2019, 10, 430. [CrossRef] [PubMed]

24. Di Salvo, C.; Pennica, F.; Ciotoli, G.; Cavinato, G.P. A GIS-based procedure for preliminary mapping of pluvial flood risk at metropolitan scale. Environ. Model. Softw. 2018, 107, 64-84. [CrossRef]

25. Soriano-Redondo, A.; Bearhop, S.; Cleasby, I.R.; Lock, L.; Votier, S.C.; Hilton, G.M. Ecological Responses to Extreme Flooding Events: A Case Study with a Reintroduced Bird. Sci. Rep. 2016, 6, 28595. [CrossRef] [PubMed]

26. Huang, K.; Yu, K. Research on key technology for 3D GIS platform of flood prevention and mitigation. J. Nat. Disasters. 2013, 22, 239-244.

27. Diakakis, M.; Pallikarakis, A.; Katsetsiadou, K. Using a Spatio-Temporal GIS Database to Monitor the Spatial Evolution of Urban Flooding Phenomena. The Case of Athens Metropolitan Area in Greece. ISPRS Int. J. Geo Inf. 2014, 3, 96-109. [CrossRef]

28. Berne, A.; Krajewski, W.F. Radar for hydrology: Unfulfilled promise or unrecognized potential? Adv. Water Resour. 2013, 51, 357-366. [CrossRef]

29. Fewtrell, T.J.; Duncan, A.; Sampson, C.C.; Neal, J.C.; Bates, P.D. Benchmarking urban flood models of varying complexity and scale using high resolution terrestrial LiDAR data. Phys. Chem. Earth Parts A/B/C 2011, 36, 281-291. [CrossRef]

30. Kulawiak, M.; Kulawiak, M.; Lubniewski, Z. Integration, Processing and Dissemination of LiDAR Data in a 3D Web-GIS. ISPRS Int. J. Geo Inf. 2019, 8, 144. [CrossRef]

31. Adeogun, A.G.; Daramola, M.O.; Pathirana, A. Coupled 1D-2D hydrodynamic inundation model for sewer overflow: Influence of modeling parameters. Water Sci. 2019, 29, 146-155. [CrossRef]

32. Gallegos, H.A.; Schubert, J.E.; Sanders, B.F. Two-dimensional, high-resolution modeling of urban dam-break flooding: A case study of Baldwin Hills, California. Adv. Water Resour. 2009, 32, 1323-1335. [CrossRef]

33. Saadi, Y. One-Dimensional Hydrodynamic Modelling for River Flood Forecasting. Civ. Eng. Dimens. 2008, 10, 51-58.

34. Cea, L.; Garrido, M.; Puertas, J. Experimental validation of two-dimensional depth-averaged models for forecasting rainfall-runoff from precipitation data in urban areas. J. Hydrol. 2010, 382, 88-102. [CrossRef]

35. Vozinaki, A.K.; Morianou, G.G.; Alexakis, D.D.; Tsanis, I.K. Comparing 1D and combined 1D/2D hydraulic simulations using high-resolution topographic data: A case29 study of the Koiliaris basin, Greece. Hydrol. Sci. J. 2017, 62, 642-656. [CrossRef]

36. Tamang, S.L.; Saikhom, V.; Bhutia, Z.T. 3D Flood Simulation System using RS\&GIS. Int. J. Eng. Res. Technol. 2014, 3, 2218-2222.

37. Costabile, P.; Costanzo, C.; De Bartolo, S.; Gangi, F.; Macchione, F.; Tomasicchio, G.R. Hydraulic Characterization of River Networks Based on Flow Patterns Simulated by 2-D Shallow Water Modeling: Scaling Properties, Multifractal Interpretation, and Perspectives for Channel Heads Detection. Water Resour. Res. 2019, 55, 7717-7752. [CrossRef]

38. Guide for Selecting Manning's Roughness Coefficients for Natural Channels and Flood Plains. Available online: https://www.wcc.nrcs.usda.gov/ftpref/wntsc/H\&H/roughness/wsp2339.pdf (accessed on 17 October 2019).

39. Costabile, P.; Macchione, F.; Natale, L.; Petaccia, G. Flood mapping using LIDAR DEM. Limitations of the 1-D modeling highlighted by the 2-D approach. Nat. Hazards 2015, 77, 181-204. [CrossRef]

40. Akan, A.O. Open Channel Hydraulics; Elsevier Press: Amsterdam, The Netherlands, 2006.

41. Julin, A.; Jaalama, K.; Virtanen, J.-P.; Maksimainen, M.; Kurkela, M.; Hyyppä, J.; Hyyppä, H. Automated Multi-Sensor 3D Reconstruction for the Web. ISPRS Int. J. Geo-Inf. 2019, 8, 221. [CrossRef]

42. Yang, C.R.; Tsai, C.T. Development of a GIS-Based Flood Information System for Floodplain Modeling and Damage Calculation. J. Am. Water Resour. Assoc. 2000, 36, 567-577. [CrossRef]

43. Singh, H.; Garg, R.D. Web 3D GIS Application for Flood Simulation and Querying Through Open Source Technology. J. Indian Soc. Remote Sens. 2016, 44, 485-494. [CrossRef]

44. Seenirajan, M.; Natarajan, M.; Thangaraj, R.; Bagyaraj, M. Study and Analysis of Chennai Flood 2015 Using GIS and Multicriteria Technique. J. Geogr. Inf. Syst. 2017, 9, 126-140. [CrossRef] 
45. Zhang, X.; He, M. Application of UAV aerial Photography Technology in Xiashan Reservoir Survey. Shandong Water Resour. 2015, 06, 11-12.

46. Petty, T.R.; Noman, N.; Ding, D.; Gongwer, J.B. Flood Forecasting GIS Water-Flow Visualization Enhancement (WaVE): A Case Study. J. Geogr. Inf. Syst. 2016, 08, 692-728. [CrossRef]

47. Adelfio, M.; Kain, J.H.; Stenberg, J.; Thuvander, L. GISualization: Visualized integration of multiple types of data for knowledge co-production. Geogr. Tidsskr. Dan. J. Geogr. 2019, 119, 1-22. [CrossRef]

48. Semmo, A.; Trapp, M.; Jobst, M.; Döllner, J. Cartography-Oriented Design of 3D Geospatial Information Visualization-Overview and Techniques. Cartogr. J. 2015, 52, 95-106. [CrossRef]

49. Chen, A.S.; Evans, B.; Djordjević, S.; Savić, D.A. A coarse-grid approach to representing building blockage effects in 2D urban flood modelling. J. Hydrol. 2012, 426, 1-16. [CrossRef]

50. Schirmer, M.; Leschik, K.; Musolff, A. Current research in urban hydrogeology-A review. Adv. Water Resour. 2013, 51, 280-291. [CrossRef]

51. Chen, Z.; Chen, N. A Real-Time and Open Geographic Information System and Its Application for Smart Rivers: A Case Study of the Yangtze River. ISPRS Int. J. Geo Inf. 2019, 8, 114. [CrossRef]

(C) 2019 by the authors. Licensee MDPI, Basel, Switzerland. This article is an open access article distributed under the terms and conditions of the Creative Commons Attribution (CC BY) license (http://creativecommons.org/licenses/by/4.0/). 